\title{
LOS SINTAGMAS NOMINALES EN TEXTOS CIENTÍFICOS ESCRITOS EN ESPAÑOL ${ }^{1}$
}

\author{
Guillermo Soto y Carlos Zenteno \\ Universidad de Chile \\ gsoto@uchile.cl
}

\begin{abstract}
Resumen
This study examines a number of textual-discoursal functions performed by noun phrases in scientific articles and students' papers written in Spanish, mainly by those which exhibit great syntactic complexity. After identifying and describing 13 micro-functions in operation in both articles published in some Chilean social and natural science journals and in papers written by university students, we propose that syntactically complex noun phrases perform 4 important discoursal-textual macro-functions: referential, predicative, textual configuration, and the hierarchical organisation of information. While the first two functions have received attention in standard Spanish semanticallyoriented text grammars, the last two seem to emerge mainly as part of a text-discourse oriented cognitive approach.
\end{abstract}

\section{Introducción}

La alta proporción de sustantivos es un rasgo característico -aunque no exclusivo- de los artículos científicos y, probablemente, del discurso científico en general. En comparación con otras variedades de lenguaje escrito, los textos científicos presentan un fuerte incremento de sustantivos y sintagmas nominales, fenómeno reconocido por diversos investigadores (cfr. Halliday y Martin, 1993). El análisis cuantitativo desarrollado en textos en inglés por Biber (1988) muestra que la prosa académica ${ }^{2}$ sólo es superada por los documentos oficia${ }^{l e s^{3}}$ en lo que dice relación con el promedio de nominalizaciones por 1.000 palabras $(35.8$ vs. 39.8) y que esta misma se ubica entre los géneros textuales con más alto promedio de sustantivos por 1.000 palabras (188.1), aunque de ninguna manera posee el mayor valor. En un estudio cuantitativo relacionado con la presente investigación, Soto, Martínez, y Sado-

\footnotetext{
1 Este trabajo es parte del proyecto DID SOC-01/01-2, "El discurso científico escrito en ciencias naturales y sociales: un estudio comparativo de los textos de especialistas y estudiantes universitarios". Algunos de sus contenidos fueron presentados de manera sintética por Carlos Zenteno en el XV Congreso de la Sociedad Chilena de Lingüística (Santiago, Universidad Metropolitana de Ciencias de la Educación,13-17 de octubre de 2003).

2 Los textos académicos estudiados por Biber (1988) abarcan las ciencias naturales, la medicina, la matemática, las ciencias sociales y de la conducta, la ciencia política, el derecho y la educación, las humanidades, y la tecnología e ingeniería.

3 Por documentos oficiales Biber entiende textos como documentos gubernamentales, informes de fundaciones, informes de industrias, etcétera.
} 
wsky (en preparación) han encontrado que, al comparar la frecuencia relativa de verbos y sustantivos en un corpus del español de Chile compuesto por textos académicos de diversas áreas de conocimiento (ciencias aplicadas, ciencias naturales, ciencias sociales y humanidades), y por textos periodísticos y cartas a medios de comunicación, la frecuencia relativa de sustantivos disminuye progresivamente desde las ciencias duras y aplicadas hacia los textos periodísticos y no especializados. Aun cuando existen traslapos -típicamente entre textos de ciencias aplicadas y naturales, por un lado, y de ciencias sociales y humanidades, por el otro-, el estudio muestra una clara progresión de mayor a menor frecuencia relativa de sustantivos en la siguiente escala jerárquicamente decreciente: ciencias aplicadas $>$ ciencias naturales $>$ ciencias sociales $>$ humanidades $>$ textos periodísticos $>$ cartas a medios de comunicación. Por otra parte, globalmente considerados, los textos que encabezan las frecuencias relativas por área disciplinaria suelen ser de profesionales mientras que los textos de estudiantes tienden a ocupar posiciones intermedias o - en el caso de humanidades- finales con respecto a este factor ${ }^{4}$.

Se han propuesto diversas interpretaciones para explicar este carácter 'nominalizador' de los artículos científicos. Todas ellas descansan en el supuesto de que el incremento de sustantivos obedece a un fuerte aumento de las nominalizaciones, es decir, de unidades relacionadas o derivadas morfológicamente de otras categorías gramaticales (triste $>$ tristeza, descubrir $>$ descubrimiento). En primer término, diversos autores han destacado que la referencia a procesos a través de sintagmas nominales, junto con el empleo de un vocabulario técnico, tendría por efecto un discurso que privilegiaría los objetos por sobre los procesos (cfr. Gross y Harmon, 1999). Esta idea ha sido extremada por Halliday y sus colaboradores, quienes, sosteniendo una suerte de relativismo discursivo, proponen que, mediante este tipo de recursos, los científicos construirían una realidad fija y determinada en que predominarían los objetos, la que sería muy distinta de la realidad del hombre común, donde los procesos desempeñan un importante papel (Halliday y Martin, 1993). En una interpretación semejante, Albentosa y Moya (2000: 465) relacionan el elevado número de nominalizaciones con la despersonalización del discurso científico, otro rasgo característico de los artículos de investigación: "la sustantivación se revela como un recurso que, al convertir los antiguos argumentos del verbo en satélites, permite suprimir la referencia a la subjetividad velando la presencia del agente, normalmente el autor o autores de la investigación".

En una aproximación alternativa, Zenteno (1996) ha planteado que la presencia en el discurso científico de un número comparativamente alto de sintagmas nominales y, consecuentemente, de nominalizaciones, pone de manifiesto la capacidad entificatoria de los especialistas. Esta capacidad cognitivo-discursiva tiene que ver con el desarrollo de la habilidad para percibir y conceptualizar los fenómenos tanto físicos como abstractos en sus correspondientes ámbitos de investigación, de un modo equivalente a la percepción y

4 La indagación realizada por Soto, Martínez y Sadowsky abarca un corpus de 2.081 archivos de textos escritos por profesionales de diversas áreas de conocimiento ( 8.352 .344 palabras); 149 archivos de textos escritos por estudiantes de las mismas áreas (1.105.800 palabras); y 4.000 archivos de textos no académicos. (3.225.813 palabras). La comparación entre sustantivos y verbos se realizó computacionalmente a partir de las frecuencias relativas de las unidades en distintas fuentes de textos académicos y no académicos. Debe subrayarse que este análisis considera como unidad los sustantivos, no las nominalizaciones ni los sintagmas nominales. Con todo, es un buen índice de la frecuencia de unidades de tipo nominal y concuerda con los análisis más finos, pero menos extensos, efectuados de manera tradicional. 
conceptualización de las entidades físicas de primer orden. Junto a ello, los especialistas también desarrollan la habilidad para configurar discursos holísticos, esto es, sintetizadores o aglutinadores de los referentes, que elaboran como parte de sus estructuras cognitivas y de su comunicación lingüística. Esta capacidad entificatoria holística es alternativa a la orientación discursivo-textual analítica, en la cual se procede a la configuración discursiva y la comunicación lingüística de los fenómenos a través de proposiciones, esto es, de unidades lógico-semánticas que suponen una composición interna discreta en argumentos y predicados. Sintácticamente, mediante la tendencia aglutinante, o sintetizadora, la identificación de los fenómenos complejos en los textos elaborados por los especialistas se formaliza a través de sintagmas nominales complejos, mientras que la segunda orientación, de carácter analítico, implica una formalización sintáctica vía cláusulas y oraciones.

Si bien el análisis cuantitativo ha logrado mostrar, con sólidas bases empíricas, el predominio de las unidades nominales en los artículos científicos, y las interpretaciones globales han propuesto explicaciones sugerentes sobre la relación entre las nominalizaciones y las funciones sociales y cognitivas del discurso científico, parecen faltar análisis detallados de las diversas funciones que las estructuras nominales desempeñan en este tipo de textos, especialmente en el caso de discursos escritos en español. El presente trabajo expone los resultados de un microanálisis cualitativo que permitió observar las funciones que las nominalizaciones y los sintagmas nominales realizan en textos científicos escritos en español. $\mathrm{El}$ análisis cubrió un corpus de 10 textos correspondientes a las áreas disciplinarias de biología, economía, psicología, geología y antropología/arqueología. Los textos fueron escritos por científicos consolidados en sus respectivos campos de investigación y publicados en revistas especializadas chilenas. Con el objeto de observar el funcionamiento en textos de sujetos no expertos, se analizaron también escritos de estudiantes de economía y antropología. En el trabajo se describen las 13 microfunciones, o usos, identificadas en el análisis, y se proponen algunas generalizaciones relativas al funcionamiento de estas unidades en el discurso científico escrito. Específicamente, se plantea que estos usos se organizan en cuatro macrofunciones, a saber: referencial o identificatoria, predicativa, textualizadora, y de organización jerárquica de la información.

En atención a su carácter básicamente empírico, en el presente trabajo no se incluye un marco teórico en un apartado especial de acuerdo con los estándares de los informes de investigación lingüística. No obstante, sí se discuten las descripciones y propuestas pertinentes a cada una de las funciones oracionales, discursivas o textuales, como también las aproximaciones a las distintas categorías de sintagmas nominales estudiados, según ellas han sido entregadas por distintos autores en el marco de sus orientaciones específicas. Tal examen se entrega en conjunto con la presentación y correspondiente discusión de los datos y hallazgos de nuestra indagación.

\section{Las funciones de los sintagmas nominales en los textos científicos}

En la investigación se identificaron trece microfunciones discursivo-textuales desempeñadas por los sintagmas nominales en los textos científicos: (1) identificación de referentes de primer orden, (2) identificación de referentes de segundo orden, (3) predicación completa o parcial, (4) predicación nominal tematizada, (5) subtópicos tematizados, (6) sustitución proposicional, (7) marcas de referentes de segundo orden, (8) conector/sustitución regresiva, 
(9) compresión multiproposicional/configuración multiproposicional en el nivel de párrafo, (10) modalización, (11) referencia duplicada, (12) referencia/predicación metaforizada, (13) titulación y subtitulación.

\subsection{Identificación de referentes de primer orden}

La identificación de referentes de primer orden -también llamados 'entidades de primer orden' (Lyons, 1977; Centeno, 1991 y 1996)-, ya sea en términos específicos o genéricos, corresponde a la función primaria de los sintagmas nominales ${ }^{5}$. Naturalmente, es frecuente encontrar en los textos científicos que la identificación de referentes de primer orden se realiza a través de sintagmas nominales complejos en los que el sustantivo aparece modificado por una o más unidades con función categorizadora o especificadora, como ocurre en los siguientes ejemplos tomados, respectivamente, de textos de biología, geología, psicología y antropología:

(1) 16 conejas de la raza Neozelandesa [sic.] blanca.

(2) Rocas plutónicas.

(3) Niños con evidencia de maltrato.

(4) El sitio Pellines.

Como se observa en este listado, los sintagmas nominales identifican no sólo animales, personas y cosas, como señala Lyons (1977), sino también lugares. La categorización y la especificación pueden ser muy complejas, atendiendo tanto a la identificación de referentes particulares como a la delimitación de subconjuntos determinados, tal y como se advierte en el siguiente ejemplo, en que los dos primeros adjetivos actúan como categorizadores ${ }^{6}$ mientras que el sintagma preposicional -que afecta al sustantivo núcleo modificado (rocas volcánicas pleistocenas)- opera como un especificador semántico locativo:

(5) Las rocas volcánicas pleistocenas de los estratos de la cordillera Lagunillas.

Los especialistas identifican, en sus respectivos dominios disciplinarios, un vasto conjunto de referentes, prácticamente imposible de precisar de modo cuantitativo, que abarca entidades tanto reales como no reales descubiertas y desarrolladas en sus investigaciones.

5 Como se sabe, la gramática tradicional definía nocionalmente la categoría léxica 'sustantivo' a partir de la función semántica de nombrar personas, animales y cosas. Si bien esta definición ha sido criticada a partir de contraejemplos evidentes como invasión, terremoto y felicidad -sustantivos que denotan, respectivamente, acción, proceso y estado-, diversos lingüistas modernos han planteado que la postura tradicional es válida si se asume una semántica de los prototipos según la cual los sustantivos típicos son aquellos que designan clases de personas, animales y cosas. Todavía más, aun cuando no todo sustantivo denota una clase de entidades de primer orden, la denotación de toda clase de entidades de primer orden se realiza a través de sustantivos. Por otra parte, la lingüística moderna progresivamente fue estableciendo una clara distinción entre las funciones sintácticas y semánticas que desempeñan las léxicas, como el sustantivo, y aquellas que cumplen los sintagmas nominales. Por tanto, en el presente trabajo se atribuye a los sintagmas nominales y no a los sustantivos las funciones de referencia (esto es, identificación) a entidades de primer orden (y más adelante, a las de segundo orden). Estos últimos, al igual que las otras clases léxicas, cumplen la función semántica de denotación (Lyons, 1995, Kearn, 2000, entre otros).

6 Obsérvese que en el ejemplo dado la modificación es jerárquica y no lineal: volcánicas modifica a rocas, y pleistocenas modifica a rocas volcánicas, como es común en los adjetivos relacionales (cfr. Demonte, 1999). 
En muchos de estos casos, los sintagmas nominales identificatorios son elaborados a partir de sustantivos núcleos denotadores ya estandarizados en la disciplina:

(6) Los estratos de la Cordillera Lagunillas.

(7) Las células primordiales de conejo.

(8) Memoria espacial a corto plazo.

(9) Las pequeñas y medianas empresas.

Finalmente, es interesante observar el empleo de nombres propios en la identificación de determinados referentes de primer orden. Además de su uso en la referencia a otros especialistas -tema de interés para los estudios de las citas en el discurso científico ${ }^{7}-$, los nombres propios pueden emplearse, ya sea de manera independiente o en combinación con sintagmas nominales, para identificar, entre otros, lugares (10) y (11), instituciones (12) y (13) y métodos (14) y (15):

(10) En Chile.

(11) La ciudad de Los Ángeles.

(12) El Ministerio de Salud.

(13) El INRA.

(14) La prueba "Child Abuse Potential Inventory".

(15) Las técnicas TEC-1 y PG-2.

\subsection{Identificación de referentes de segundo orden o 'pseudo-entidades': acciones, pro- cesos, estados}

Si bien la referencia a entidades de segundo orden -o 'pseudo-entidades' (Zenteno, 1992; Zenteno, 1996), es decir, fenómenos o eventos visualizados como si fueran de primer ordense encuentra presente en todos los ámbitos de la comunicación lingüística, la alta frecuencia de este proceso, como también su gran complejidad sintáctica, parece ser uno de los rasgos sobresalientes de los artículos científicos (cfr. Halliday y Martín, 1993). En efecto, es común encontrar en esta variedad de textos sintagmas que refieren a acciones, procesos y estados, sobre la base de la nominalización de verbos y adjetivos, principalmente:

(16) Las estimaciones.

(17) La ausencia de un criterio único y ampliamente aceptado.

Diversos autores se han ocupado de este fenómeno. Así, a partir del primer modelo propuesto por Chomsky (1957), investigadores como Lees (1960) plantean que distintos

7 La referencia a otro investigador suele conducir, finalmente, a una referencia a cierta obra específica, a un conjunto de obras o, incluso, a modelos, teorías o, más ampliamente, pensamientos de ese autor.

8 En el presente estudio se incluyen y describen los sintagmas preposicionales constituyentes de cláusulas como una subclase de sintagmas nominales típicamente acompañados de una preposición o postposición que opera como marca sintáctica. Esta aproximación contrasta con la propuesta generativa del modelo de 'rección y ligazón' que asigna a la preposición el papel de núcleo del sintagma preposicional (cfr. Radford 1988, Demonte 1991). Por otra parte, en oposición a la gramática tradicional e, incluso, a varios modelos contemporáneos que describen los nombres propios como una subclase de sustantivos, ellos serán descritos aquí como instancias de una subclase de sintagmas nominales (Zenteno 1999 y 2002). 
tipos de nominalización pueden ser explicados como derivaciones o transformaciones de oraciones en sintagmas nominales. La propuesta 'transformacionalista' de Lees fue discutida y respaldada por los semanticistas generativos. Por su parte, Chomsky (1970) rebatiría la tesis transformacional de Lees sosteniendo una aproximación 'lexicalista' al fenómeno, de acuerdo con la cual las nominalizaciones tendrían su origen en la formación de los sustantivos en el componente léxico de la gramática.

En el marco de la gramática sistémico-funcional de Halliday $(1985,1994)$, el fenómeno se describe como un proceso más amplio que este autor denomina 'metáfora gramatical'. Según su propuesta, toda configuración semántica posee al menos una realización 'congruente' en el componente léxico-gramatical. Así, las personas, animales, y objetos concretos y abstractos, que se constituyen en los participantes en la cláusula, son expresados congruentemente por sustantivos, mientras que las acciones, eventos, procesos mentales y relaciones, que configuran los procesos en la cláusula, se expresan congruentemente mediante verbos. La metáfora gramatical consiste en una transferencia en virtud de la cual una configuración semántica pasa a ser expresada por un elemento léxico-gramatical no congruente. El uso de metáforas gramaticales que involucran sustantivos sería, de acuerdo con Halliday (1985, 1994), característico del lenguaje adulto en oposición a la expresión congruente de los niños. Su origen y desarrollo, sin embargo, no radicaría en el lenguaje adulto cotidiano sino en el discurso especializado del científico, según proponen Halliday y Martin (1993):

Este tipo de metáfora se encuentra particularmente en el discurso científico, y puede haber evolucionado primero que todo en ese contexto. Está ya comenzando a aparecer en los escritos de los científicos griegos antiguos; desde ellos fue transferido al latín clásico y luego al latín medieval; y ha continuado desarrollándose -incluso a un mayor grado- en el italiano, inglés, francés, alemán, ruso y las otras lenguas europeas a partir del Renacimiento. (pág. 80)

La causa de este desarrollo radicaría, según los autores, en la necesidad de encontrar una expresión gramaticalmente adecuada de las secuencias de razonamiento características del proceso de investigación científica. La expresión de procesos, eventos y estados vía la nominalización permitiría vincular antecedentes y consecuentes como participantes en una sola cláusula, mediante un verbo que expresaría de qué manera los segundos resultan de los primeros. Esto facilitaría la construcción de cadenas textuales en las que, vía la nominalización, una nueva cláusula retomaría sintéticamente información dada con anterioridad y aportaría, también a través de una metáfora gramatical nominal, información nueva. Esto se ilustra en el siguiente ejemplo, tomado de Halliday y Martín (1993, pág. 81), en el que la segunda cláusula y la tercera nominalizan el contenido presentado analíticamente en la primera:

(18) The atomic nucleus absorbs and emits energy only in quanta, or discrete units. Each absorption marks its transition to a state of higher energy, and each emission marks its transition to a state of lower energy.

Como puede advertirse, las metáforas nominales surgirían de presiones derivadas de la elaboración textual de un discurso multiproposicional. Como se verá más adelante, nuestro análisis confirma el empleo de nominalizaciones complejas como un efectivo recurso 
de textualización que opera, entre otros, en procesos como la tematización, la sustitución proposicional, la organización del discurso y la compresión multiproposicional. Con todo, el reconocimiento de que se está ante un fenómeno de carácter discursivo-textual y no puramente gramatical no es consistente con el intento de caracterizarlo en términos únicamente léxico-gramaticales. Tanto la identificación de referentes complejos como la referencia anafórica y catafórica en el desarrollo textual son actos pragmáticos que demandan, por tanto, una descripción en términos discursivos.

Zenteno (1991 y 1996) caracteriza la nominalización mediante una aproximación cognitivo-discursiva. Basándose, en primer término, en la ontología propuesta por Lyons (1977), sostiene que la función básica de los sintagmas nominales es la identificación de los referentes de primer orden (concretos o abstractos). Esta función es luego extendida por los usuarios a la identificación sintética de eventos primarios vía su conversión a referentes de segundo orden o pseudo-entidades (e.g., el descubrimiento de América), como alternativa a la identificación analítica de los eventos primarios, referentes de tercer orden o no-entidades (e.g., Colón descubrió América en 1492). Como se explicó anteriormente, mientras los sintagmas nominales cumplen en el discurso funciones identificatorias de referentes de primer y de segundo orden, de manera específica o genérica, los sustantivos designan (esto es, denotan) clases de tales referentes. En otras palabras, mientras los sintagmas nominales identifican referentes determinados -específicos o genéricos- en una situación comunicativa dada, los sustantivos se constituyen, en último término, en rótulos de conocimiento almacenado (conceptos) en la memoria semántica de largo plazo.

El funcionamiento pragmático de los sintagmas nominales complejos permite explicar la presencia en los textos científicos de sintagmas que refieren a entidades de segundo orden que pueden ordenarse en distintos puntos de un continuum que va desde lo específico a un tiempo y un lugar a lo ya considerado como conocimiento general en la disciplina. Los ejemplos que siguen ilustran esta secuencia:

(19) Una actividad eruptiva freatomagmática de tipo Bandai-San la que produjo, casi simultáneamente, flujos piroclásticos turbulentos, de tipos de oleadas de base húmeda, compuestos de cenizas basálticas negras cuyos depósitos primarios se han denominado Arenas Negras de Trupán-Laja.

(20) La acción glaciaria del Pleistoceno inferior en rocas de las formaciones terciarias Cura-Mallín y Trapa-Trapa.

(21) El análisis de restos botánicos procedentes de dos pozos de sondeo y un pozo de control del sitio Pellines 1.

(22) Caracterización, aislamiento y cultivo de células germinales primordiales de conejo.

(23) Un modelo interdisciplinario de detección, prevención, y tratamiento del maltrato infantil a partir del sistema escolar.

El ejemplo (19) se refiere a un suceso específico que tuvo lugar en un tiempo y espacio determinados y es irrepetible. (20), por su parte, informa de un conjunto de eventos que ocurrieron en un lugar particular a lo largo de un período extenso pero específico. En el caso de (21), se comunica un proceso realizado en un tiempo y un lugar específicos, que, sin embargo, es, en sus aspectos pertinentes, replicable por el mismo u otros especialistas. (22) da cuenta de una serie de acciones cuyas propiedades temporales y espaciales específicas no son relevantes, y que se informan a la comunidad científica con estatus genérico y con 
la pretensión de ser replicables. Finalmente, (23) propone un conjunto de procedimientos que pretenden constituirse como un método de acción en la disciplina. Obsérvese, incidentalmente, que casos como (23) son candidatos a ser comunicados mediante nominales complejos (p. ej., análisis factorial) e incluso siglas y acrónimos.

\subsection{Predicación completa o parcial (predicadores semánticos centrales de proposicio- nes)}

Otra microfunción de los sintagmas nominales en los artículos científicos es la de constituirse en el predicado de algunas proposiciones contenidas en cláusulas, en que la función de predicador sintáctico es realizada por un elemento verbal, tal y como puede observarse en los siguientes ejemplos, donde (24) y (25) muestran instancias de predicación completa:

(24) La historia geológica del cuaternario en el tramo superior del valle del río Laja corresponde a [una compleja interrelación entre volcanismo, procesos de remoción en masa y rudimentarios aluvi-fluviales]

(25) El volcán Antuco corresponde a [ un estrato volcán mixto y compuesto, de composición basáltica y andesítico-basáltica, cuya actividad se inició ca. 130.000 a A.P.]

Como se advierte, en estos casos el verbo aparece semánticamente debilitado y la predicación semántica se realiza mediante los sintagmas nominales que lo siguen. Es clara la proximidad funcional entre el verbo corresponde a y el verbo ser. En otra parte, hemos denominado a estas construcciones "pseudoatributivas", toda vez que -tal y como ocurre con las estructuras atributivas canónicas- en estos casos el sintagma verbal comunica contenidos gramaticales como tiempo, aspecto y modo, mientras que el sintagma nominal absorbe plenamente la función predicativa semántica.

También es posible que el sintagma nominal constituya una parte importante de la predicación de la cláusula, como se observa en los siguientes casos:

(26) El colapso gravitacional (lateral del edificio [el volcán Antuco]) fue lel resultado del una actividad eruptiva freatomagmática de tipo Bandai-San la que produjo, casi simultáneamente, flujos piroclásticos turbulentos, de tipos de oleadas de base húmeda, compuestos de cenizas basálticas negras cuyos depósitos primarios se han denominado Arenas Negras de Trupán-Laja.

(27) Para ello se tendría que [hacer el supuesto poco plausible de] que, por ejemplo, la distribución de habilidades empresariales es distinta en cada sector o que existen sectores que requieren más habilidades, o tiempo, que otros.

(28) Se [tiene evidencia de] que las empresas pequeñas son prevalecientes en algunos sectores de la economía y relativamente escasas en otros.

Los ejemplos muestran que, mientras la predicación semántica se encuentra desplazada a un sintagma nominal sintácticamente ligado al verbo, la función de predicado sintáctico es cumplida por un 'verbo básico' (Quirk et alii, 1985) como ser. En el caso (26), el sintagma nominal el resultado de, constituyente de la predicación, es una derivación del verbo resultar de; en (27), hacer el supuesto (poco plausible) de deriva de suponer; y en (28), tiene 
evidencia de se relaciona, en este caso, con saber, dado que las evidencias (esto es, pruebas) son la base del conocimiento empírico.

\subsection{Predicación nominal tematizada}

Las nominalizaciones también se emplean como un recurso para tematizar predicados, fenómeno que no parece haber sido tratado con anterioridad por otros investigadores. Mediante un sustantivo deverbal, el núcleo del predicado oracional se desplaza a una posición inicial, típica del tema oracional, como se ilustra en (29):

(29) [La justificación de esta política activa] radica en una diversidad de problemas que enfrentarían las PYMEs y que las constituyen en sujeto especial de apoyo estatal.

(29) entrega la misma matriz proposicional que (29'):

(29') Esta política activa se justifica por una diversidad de problemas que enfrentarían las PYMEs y que las constituyen en sujeto especial de apoyo estatal.

Sin embargo, la estructuración de la información es distinta pues mientras en la última se predica acerca del referente tematizado la política activa, en la primera el tema es la justificación de esa política. Este uso pone de manifiesto el poder de las nominalizaciones como recurso configurador, además de sintetizador, del texto/discurso, en cuanto permite la síntesis de un grupo de proposiciones 'analíticas'.

\subsection{Subtópicos tematizados (derivados de predicación)}

Otra importante microfunción que desempeñan las nominalizaciones es la de servir como recurso de tematización de subtópicos, contribuyendo, de esta manera, a la progresión temática y topical del texto. Como puede anticiparse, el proceso cubre tanto instancias de progresión temática lineal como casos de tema dividido (cfr. Bloor y Bloor, 1995). Mientras el ejemplo (30) muestra la configuración de un tema a partir de un predicado remático anterior, recurso estándar de la progresión temática, el (31) y el (32) presentan un patrón de progresión temática vía tema dividido, que contribuye a la organización jerárquica textual. En este tipo de casos, el contenido remático se divide en subtópicos que se explicitan en los temas siguientes. En el ejemplo (31), el rema, además de identificar los referentes en cuestión, explicita los dos subtópicos discursivos que se desarrollarán; en el (32), en cambio, el rema identifica sólo el conjunto de los referentes implicados, no sus miembros.

(30) Los estratos de la Cordillera Lagunillas y del Cerro Pan de Azúcar se interpretan como secuencias de lava e ignimbritas escoriáceas, que engranan hacia el occidente con materiales volcanoclásticos que representan las típicas facies mixtas medias y distales de deposición continental de un arco volcánico. [Esta interpretación] es avalada por dos sondajes efectuados ...

(31) [El cono poligénico de Quilleco] está integrado por dos unidades: [una inferior eminentemente volcanoclástica] y [una superior constituida por depósitos fluviales e intercalaciones volcanoclásticas distales] 
[La unidad inferior] corresponde a un conjunto de ignimbritas escoriáceas, con intercalaciones de tobas, brechas y conglomerados consolidados (probablemente facies laháricas distales) que, localmente muestran inclinaciones primarias de hasta 12 [grados].

[Esta sucesión de niveles volcanoclásticos consolidados que afloran en el sector central y occidental del área estudiada] incluye ...

[Párrafo]

[Párrafo]

[Párrafo]

[Párrafo]

... [Estos últimos niveles] corresponden a [la unidad o secuencia superior del Cono de Quilleco]

(32) La literatura sobre la importancia relativa de las pequeñas empresas se ha desarrollado sobre [tres áreas de investigación principales] (Acs y Audretsch,1990). [La primera] está relacionada con los determinantes de la distribución de tamaño de empresas dentro de cada industria ... [Una segunda área de investigación] enfatiza la importancia de las estructuras de costos de las empresas en la determinación de la escala o tamaño óptimo de las firmas... Finalmente, [una tercera línea de investigación] explora la relación entre el tamaño de la firma y la estrategia empresarial...

Es interesante observar que en (31) el tema la unidad o secuencia superior del Cono de Quilleco, de estatus claramente temático (esto es, dado, dependiente de contexto, con menor dinamismo comunicativo) aparece en posición final, lugar normalmente reservado a la información remática (esto es, nueva, independiente de contexto, con mayor dinamismo comunicativo). El segmento textual que se organiza a partir del primer enunciado comprende ocho párrafos. Desde el segundo, se inicia una compleja descripción del Cono de Quilleco, en la que junto con aportar información acerca de sus distintos niveles en sentido ascendente, se sintetizan estudios anteriores sobre los mismos tópicos, presentándose los investigadores con sus respectivos aportes. Puede plantearse que el desplazamiento a posición remática del tema la unidad o secuencia superior del Cono de Quilleco obedecería a la necesidad de los autores por dar cierre a la organización topical establecida inicialmente.

\subsection{Sustitución proposicional (prospectiva o regresiva)}

Otro uso ligado con la resolución de problemas de estructuración informativa en el texto es el que se advierte en instancias como (33) y (34), donde las frases nominales entre corchetes facilitan la progresión temática y la subtopicalización al sintetizar una o más proposiciones anteriores. En (33), la frase nominal esta política activa, construida con un sustantivo genérico modificado y un determinante semánticamente pronominal, establece una anáfora con las proposiciones formalizadas vía oraciones en el párrafo anterior. En (34), por su parte, la frase nominal estos problemas, conformada por un sustantivo genérico y un 
determinante semánticamente pronominal, marca la referencia anafórica con la proposición inmediatamente anterior, presentada en subrayado.

(33) [ Las pequeñas y medianas empresas (PYMEs) destacan como uno de los sectores de la economía que tradicionalmente han sido sujetos de programas especiales de apoyo por parte del Gobierno. Durante los últimos años, un volumen importante de recursos estatales se ha destinado, por ejemplo, a programas de asistencia técnica y programas de fomento productivo para este grupo de empresas.]

La justificación de [esta política activa] radica en una diversidad de problemas que enfrentarían las Pómez y que las constituyen en sujeto especial de apoyo estatal.

(34) Los resultados obtenidos, utilizando tanto su participación en las ventas como en el número de empresas, indican que la presencia de empresas pequeñas es menor en aquellos sectores más intensivos en capital físico y capital humano. Sin embargo, pueden compensar [estos problemas] a través de una intensificación del capital humano de su fuerza de trabajo y de una mayor flexibilidad para enfrentar los ciclos expansivos.

En estos casos, nos encontramos ante procesos identificatorios cuyo rasgo distintivo es que la variante analítica (o proposicional) y la sintética (o nominal) se presentan secuencialmente en un segmento del texto. En otras palabras, el proceso se origina en el propio escrito a partir de la identificación, vía oraciones, de determinados referentes complejos que son referidos más adelante por una estructura nominal sintética con función referencial anafórica. Esto implica que el proceso entificatorio no sólo desempeña un papel importante para identificar referentes de segundo orden, como se había indicado anteriormente, sino que, junto con ello, contribuye a la organización informativa del texto/discurso, una función reconocida por Halliday y Martín (1993) y Zenteno (1996).

A nuestro juicio, podemos distinguir dos dimensiones funcionales en esta contribución: una de tipo horizontal o local y otra vertical o global. Por una parte, como ya se ha indicado, la entificación favorece la progresión secuencial, permitiendo la introducción de una nueva unidad informativa, fenómeno que constituye una práctica estándar en los textos científicos contemporáneos (cfr. Halliday y Martín, 1993). Además, en los casos analizados la entificación facilita la estructuración jerárquica, toda vez que integra en un superconjunto inmediato la información aportada por la o las proposiciones anteriores. En otras palabras, este tipo de entificación no sólo permite configurar segmentos localmente coherentes sino que también opera en la construcción de la coherencia global del discurso, al explicitar unidades macroproposicionales (cfr. van Dijk, 1983).

\subsection{Marcas de referentes de segundo orden (marcas prospectivas y regresivas)}

Mediante el empleo de un sintagma nominal es posible convertir en referentes de segundo orden un conjunto de proposiciones explicitadas analíticamente en el texto y formalizadas vía cláusulas. En estos casos, el sintagma nominal marca, primero, un proceso (id)entificatorio y, luego, un proceso de categorización conceptual realizado por el enunciador, que con frecuencia agrupa las proposiciones en relación con su función en el discurso o en el texto (e.g., objetivos, causas, razones, consecuencias), tal y como se ilustra en los siguientes ejemplos: 
(35) [ Los objetivos de este estudio] fueron:

Caracterizar immunohistoquímicamente las CGP de conejo en sus distintas etapas embrionarias "in vivo".

2) Reconocer el lugar óptimo para obtener estas células según edad embrionaria.

Evaluar si las células nutricias murinas permiten la proliferación y sobrevivencia de las CGP en cultivo" in vitro".

(36) Nuestro estudio se desarrolló en conejo por [las siguientes razones]: 1) En esta especie la diferenciación de las CGP ocurre durante la gastrulación... y antes de la implantación... 2) El gran tamaño del disco embrionario ofrece una mayor resolución para definir posición y número de CGP... 3) Los procesos de morfogénesis y diferenciación sexual de la gónada son muy similares con el desarrollo del embrión humano...

Como puede observarse en los ejemplos, a través de esta microfunción se realiza un proceso de síntesis de la información presentada analíticamente en determinados segmentos textuales. El proceso permite cohesionar en el texto secuencias de proposiciones que pasan, en consecuencia, a estar subordinadas a categorías discursivas amplias, normalmente estandarizadas en el quehacer científico. Tal y como indicamos respecto de la microfunción anterior, junto con contribuir a otorgar una mayor coherencia local a determinados segmentos textuales, las marcas entificatorias ponen de manifiesto la integración jerárquica de la información, contribuyendo a la coherencia global del discurso. Estas marcas parecen operar en un nivel de generalización mayor que el de la sustitución pronominal, toda vez que integran los contenidos proposicionales en categorías más amplias que refieren a constituyentes básicos de procesos característicos de la investigación y comunicación científicas.

\subsection{Conector /sustitución regresiva}

Otro uso de un subconjunto de sintagmas nominales es la explicitación de una relación de conectividad entre dos proposiciones o dos conjuntos proposicionales, establecida sobre la base de una sustitución regresiva que entifica la primera proposición (o conjunto proposicional), categorizándola, frecuentemente, por su función discursiva (e.g., razón), como se observa en el ejemplo (37):

(37) Aun cuando tradicionalmente se ha utilizado la fosfatasa alcalina (FA) para marcar células germinales primordiales, no todas las células fosfatasa alcalina positivas de embriones tempranos, contribuyen a la población de CGP... [Por tal razón] se utilizaron además, dos anticuerpos monoclonales no comerciales, como marcadores de las células germinales primordiales.

En este tipo de casos, el sintagma nominal opera discursivamente como un conector interoracional. A diferencia de los miembros de esta última categoría, sin embargo, conserva tanto las funciones referenciales como sintácticas propias de su clase. Es interesante observar, en el ejemplo, que el sintagma nominal ocupa la posición de tópico de la segunda cláusula, característica de los complementos de causa y de finalidad, que explicitan las causas, propósitos y motivaciones de los procesos. Este empleo de sintagmas nominales topicales como equivalentes funcionales de conectores es frecuente en el discurso escrito 
académico, donde también se utilizan otras expresiones de conectividad ya estandarizadas, como por ello y como consecuencia de lo anterior, entre otras.

\subsection{Compresión multiproposicional / configuración multiproposicional en el nivel de párrafo}

Los sintagmas nominales desempeñan también una importante función de economía textual al permitir la integración de secuencias de proposiciones que, de otro modo, habrían sido formalizadas vía cláusulas independientes. El ejemplo (38) muestra que mediante este proceso es posible, incluso, construir párrafos completos:

(38) También, se reconocen [otras unidades de relleno menores, conformadas por materiales detríticos y volcanoclásticos no consolidados, que revelan la ocurrencia de otros importantes procesos volcánicos y fluviales postglaciales, ligados a la evolución prehistórica del volcán Antuco, el cual se edificó en las nacientes del valle del río Laja.]

En el ejemplo, a partir del sintagma nominal otras unidades de relleno menores, ubicado en el rema de la cláusula principal, se procede a presentar, mediante cláusulas subordinadas, una secuencia jerárquica de subtópicos que se encadenan, en su mayoría, a través de una progresión temática estándar de tematización del rema anterior.

\subsection{Modalización}

En el discurso científico, los sintagmas nominales también se emplean de modo entificatorio en la expresión de algunos tipos de modalidad tanto epistémica como apreciativa (e.g., posibilidad, probabilidad, obligación, interés). Es interesante apreciar el proceso derivacional implicado a partir del punto en que un verbo o adjetivo modal puede progresivamente transformarse en un sintagma nominal que cumple la misma función semántico-pragmática modalizadora. En estos casos, el sintagma nominal sustituye a un adjetivo predicador en una construcción atributiva, proceso que puede advertirse en el ejemplo (39), donde el predicado será más probable que se relaciona con el sintagma nominal la probabilidad de (que).

(39) Modelo teórico

Una forma de entender el fenómeno de la existencia de firmas pequeñas, con escalas menores a las óptimas, es pensar en términos de un modelo de innovación tecnológica, cuya unidad relevante no es la empresa, sino los agentes individuales, digamos un trabajador. Este agente tiene la posibilidad de desarrollar una innovación dentro de la firma, en la que ganará un salario $w$, o formar una empresa con el nuevo conocimiento que es capaz de generar, por lo cual recibirá una utilidad esperada $\mathrm{p}$. Si estos dos valores son relativamente parecidos, [la probabilidad de que] el individuo se apropie de este conocimiento creando una nueva firma, será relativamente bajo. Por el contrario, si el valor esperado de la utilidad es significativamente superior a su salario,[será más probable que] el individuo se transforme en empresario.

Siguiendo a Audrestch (1998), [la probabilidad de] crear una nueva empresa va a estar dada por:

(1) $\quad \mathrm{P}(\mathrm{e})=\mathrm{f}(\pi \omega)$ 


\subsection{Referencia duplicada}

En el corpus examinado se han encontrado instancias de un particular fenómeno textual que denominaremos 'referencia duplicada'. Se trata de sintagmas nominales que aparecen en construcciones como El gobierno debe buscar una solución urgente al tema (problema) del desempleo, donde el sintagma nominal identificatorio principal se subordina sintácticamente a otro que lo categoriza en términos discursivos, como puede apreciarse en (40):

(40) Una forma de entender [el fenómeno de la existencia de firmas pequeñas, con escalas menores a las óptimas], es pensar en términos de un modelo de innovación tecnológica...

Este uso, de acuerdo con nuestra observación, se da en distintas variedades de lenguaje, tanto orales como escritas. Es posible que este tipo de construcciones constituyan, en la configuración textual-discursiva, marcas de focalización mediante las cuales el enunciador proceda a destacar un segmento informativo particular.

\subsection{Referencia / predicación metaforizada}

Algunos sintagmas nominales presentes en el discurso científico establecen un modo de referencia que podemos categorizar como metafórico. En estos casos, como se ilustra en el ejemplo (41), una entidad determinada es identificada a través de una expresión metafórica formalizada vía un sintagma nominal: un primer edificio volcánico / el gran cono; un anfiteatro; un cono central posterior. Además, las expresiones metafóricas nominales pueden participar en la configuración de predicaciones, como se observa en (42): el colapso lateral del edificio, en forma de una gran herradura.

(41) [El volcán Antuco] consta de dos unidades principales: [un primer edificio volcánico] (Antuco 1), denominado ['el gran cono'] (Domeyko, 1846) o volcán Laja por Bruggen (1941), que culminó con la formación de [un anfiteatro] y [un cono central posterior] (Antuco 2)...

(42) [EI volcán Antuco] consiste en un cono basáltico a andesítico... de más de 2.000 $\mathrm{m}$ s.n.m. de altura actual y un diámetro basal de $12 \mathrm{~km}$ edificado sobre sustrato de rocas estratificadas miocenas y materiales volcánicos de la Sierra Velluda. Su evolución culminó, a comienzos del Holoceno, con [el colapso lateral del edificio] que alcanzaba ca. 3.200 m s.n.m. y que dejó truncado su cono con [un anfiteatro] de $4 \mathrm{~km}$ de diámetro abierto hacia el oeste [en forma de una gran herradura].

\subsection{Titulación y subtitulación}

En cuanto a su uso en títulos y subtítulos, en todos los trabajos de especialistas examinados, y prácticamente en todos los de estudiantes, los sintagmas nominales se emplearon para identificar los contenidos referenciales, esto es, topicales, del discur- 
so $^{10}$. Así, fueron recurrentes títulos como Caracterización, aislamiento y cultivo de células germinales primordiales de conejo, o Motivación: su efecto sobre la estrategia de solución del laberinto octogonal, en los que el sintagma nominal opera como una macroproposición que sintetiza la macroestructura o tema discursivo del texto (cfr. van Dijk, 1983). Los títulos de los trabajos examinados se categorizaron como descriptivos del tópico, con dominancia de la función transaccional por sobre la interaccional (cfr. Brown y Yule, 1983), un resultado que concuerda con estudios previos según los cuales ha existido una tendencia progresiva a títulos más descriptivos y más extensos en los artículos científicos. En el caso de los estudiantes, algunos títulos fueron, sin embargo, poco específicos: Evaluación de una experiencia de desarrollo, Globalización y pobre$z a$, Contaminación y economía, manifestándose una tendencia a referencias globales o genéricas que merece un estudio aparte.

\section{Conclusión: las macrofunciones de los sintagmas nominales en los textos científicos}

A nuestro juicio, las funciones expuestas hasta aquí configuran cuatro macrofunciones básicas, a saber: referencial o identificatoria, predicativa, textualizadora y de organización jerárquica de la información. En efecto, como se desprende del análisis efectuado, los sintagmas nominales no sólo cumplen la función predicativa y la función primaria de identificación del amplio número de referentes configuradores del tópico del discurso. Junto a ello, desempeñan un papel relevante en la organización textual y discursiva contribuyendo tanto al encadenamiento de los subtópicos como a la configuración paradigmática o jerárquica del discurso.

En relación con la macrofunción referencial, y como se señaló anteriormente, el empleo de los sintagmas nominales en la identificación de entidades de segundo orden, típicamente referentes abstractos específicos de las disciplinas, ha sido propuesto como uno de los rasgos característicos del discurso científico. En este sentido, ser competente en una disciplina implica, entre otras capacidades, conocer una terminología determinada, normalmente codificada por sustantivos. Nuestro estudio muestra, sin embargo, que, en consonancia con lo expuesto por Halliday y Martin (1993), existen funciones identificatorias que surgen localmente en una instancia discursiva con el fin de favorecer la presentación y la progresión compactas de la información. En estos casos, la macrofunción identificatoria se pone al servicio de la macrofunción textualizadora.

El extenso empleo de sintagmas nominales predicativos constituye otra característica de los textos científicos. Si bien los sintagmas nominales predicativos no son excepcionales en español (p. ej., Pablo es jardinero), nuestro estudio muestra que en el discurso científico escrito las predicaciones nominales alcanzan gran complejidad y desempeñan un importante papel en la expresión de gran parte del contenido informativo de los textos.

10 De 42 trabajos de estudiantes de antropología y de economia, sólo en dos aparecen títulos con infinitivo inicial: Retomar la agenda del desarrollo y Educar en valores, los que, incluso, pueden ser considerados nominalizaciones: El retomar... Este recurso se observa también minoritariamente en títulos de trabajos de expertos. Otro caso interesante, en trabajos de alumnos, es el título En torno a: Lo cotidiano en la sobrevivencia, donde el pronombre lo nominaliza el adjetivo cotidiano. Finalmente, un trabajo se tituló en mapudungun. 
Por otra parte, el concepto de macrofunción textualizadora cubre no sólo los usos de los sintagmas nominales como recursos cohesivos de correferencia sino también su empleo en la sustitución proposicional -que, como hemos mostrado, no se limita a las formas pronominales- y su uso en la conectividad textual -que no se restringe a los conectores y conjunciones-. Junto a lo anterior, el presente trabajo ha puesto de manifiesto el papel central de los sintagmas nominales tanto en la constitución de la progresión temática como en el encadenamiento de los subtópicos discursivos.

En cuanto al papel de los sintagmas nominales en la organización jerárquica de la información, éste es evidente en su empleo en títulos y subtítulos, donde operan como macroproposiciones que explicitan la macroestructura semántica propuesta por el autor o los autores del texto. Esta macrofunción se advierte también en otras microfunciones, como la predicación nominal tematizada o el establecimiento de temas de subtópico. En estos usos, y otros semejantes, los sintagmas nominales sintetizan segmentos de información textual e informan al lector respecto del estatus de cierta información en la organización jerárquica global del discurso.

De lo anterior se concluye que en muchos usos los sintagmas nominales desempeñan simultáneamente más de una macrofunción. Esta operatividad múltiple se advierte en microfunciones como la de sustitución proposicional, donde un sintagma nominal establece una relación de correferencia, típicamente anafórica, con una proposición o un conjunto de proposiciones, lo que permite cohesionar dos segmentos textuales mayores y, junto a ello, sintetizar la información previamente entregada. En este sentido, los usos o microfunciones concretas instrumentan macrofunciones que, con frecuencia, pueden distinguirse sólo de manera analítica.

Si el análisis hasta aquí expuesto es correcto, de éste se desprende que ciertas caracterizaciones tradicionales del funcionamiento de las unidades lingüísticas no tienen validez absoluta, al menos en el plano textual-discursivo. Al respecto, nuestro estudio muestra, por ejemplo, que, como se sostiene en el dominio de la semántica lingüística y en el de la semántica formal, la función predicativa no es desempeñada tan sólo por sintagmas verbales, adjetivos o preposicionales sino también por sintagmas nominales complejos. Por otro lado, la dicotomía establecida entre unidades de contenido (e.g., sintagmas nominales y sintagmas verbales) y unidades de función (e.g. conjunciones y conectores) -o, más recientemente, entre unidades de representación y de computación o procesamiento- no es capaz de dar cuenta del potencial funcional de los sintagmas nominales, que, con frecuencia, junto con identificar entidades, también contribuyen a la construcción textual, facilitando de este modo el procesamiento del texto-discurso.

El presente trabajo ha intentado dar cuenta del gran poder funcional de los sintagmas nominales en el plano textual-discursivo. A partir del examen de textos genuinos, se ha tratado de demostrar que el empleo de estas estructuras no se restringe a la función identificatoria de referentes de primer y de segundo orden y a la función predicativa, sino que se extiende a funciones de elaboración discursiva y organización textual. Sin embargo, si bien se han destacado algunas importantes microfunciones de los sintagmas nominales en textos científicos -que otras descripciones parecen no haber tratado suficientemente-, en el desarrollo de nuestra investigación hemos encontrado otros usos en distintos niveles de elaboración del mensaje (e.g., cuantificadores intrasintagmáticos, nominalizadores de verbos auxiliares), los que requieren de una descripción independiente. Tampoco hemos caracterizado, en esta 
oportunidad, la incidencia funcional de las preposiciones que marcan determinados sintagmas nominales, aun cuando esta situación fue tangencialmente mencionada al tratar los sintagmas nominales en posición topical. Finalmente, es necesario señalar que en nuestra propuesta de cuatro macrofunciones básicas no se ha incluido la función discursiva que cumplen ciertos sintagmas nominales modalizadores. Es posible que este empleo constituya, por sí mismo, una macrofunción, toda vez que, como han mostrado las investigaciones sobre hedging, en los textos científicos la evaluación de la información es un nivel relevante en la configuración del mensaje (cfr. Soto, 2002). Con todo, más allá de las limitaciones expuestas, creemos que el presente trabajo, al caracterizar los sintagmas nominales a partir de sus funciones en la configuración discursivo-textual, puede contribuir a un proyecto más amplio tendiente a una caracterización alternativa de categorías gramaticales básicas, en una perspectiva cognitivo-funcional que considere el papel que éstas desempeñan en la construcción del discurso.

\section{Referencias Bibliográficas}

Albentosa, J. I. y A. J. Moya (2000): "La reducción del grado de transitividad de la oración en el discurso científico en lengua inglesa", Revista Española de Lingüística, 30 (2), págs. 445468.

Biber, D. (1988): Variation across speech and writing. Cambridge, Cambridge University Press.

Bloor, T. y M. Bloor (1995): The functional analysis of English: A Hallidayan approach. Londres, Edward Arnold Press.

Brown, G. y G. Yule (1983): Discourse analysis. Cambridge, Cambridge University Press.

Chomsky, N. (1957): Syntactic structures. La Haya, Mouton and Company.

Chomsky, N. (1970): "Remarks on nominalization". En Readings in English transformational grammar. Washington, D.C., Georgetown University Press.

Demonte, V. (1991): Teoria sintáctica: de las estructuras a la rección. Madrid, Editorial Síntesis.

Demonte, V. (1999): "El adjetivo: clases y usos. La posición del adjetivo en el sintagma nominal". En I. Bosque y V. Demonte (dirs.): Gramática descriptiva de la lengua española. Madrid, Espasa, págs. 129-215.

van Dijk, T. (1983): La ciencia del texto. Barcelona, Paidós.

Gross, A. G. y J. E. Harmon (1999): "What's right about scientific writing". The Scientist, 13 (24), págs $20-21$.

Haegeman, L. (1991): Introduction to government and binding theory. Oxford, Blackwell Publishers. Halliday, M. A. K. (1985): An introduction to functional grammar. Londres, Edward Arnold.

Halliday, M. A. K. (1994): An introduction to functional grammar (2 $2^{a}$ edición). Londres, Edward Arnold.

Halliday, M. A. K. y J. R. Martín (1993): Writing science. Literacy and discursive power. Pittsburgh, University of Pittsburgh Press.

Kearns, K. (2000): Semantics. New York, St. Martin’s Press/Palgrave.

Lees, R. (1960): The grammar of English nominalizations. La Haya, Mouton and Company.

Lyons, J. (1977): Semantics. Vols. 1 y 2. Cambridge, Cambridge University Press.

Lyons, J. (1995): Linguistic semantics: An introduction. Cambridge, Cambridge University Press.

Radford, A. (1988): Transformational grammar: A first course. Cambridge, Cambridge University Press.

Quirk, R., S. Greenbaum, G. Leech y J. Svartvik (1985): A comprehensive grammar of the English language. Harlow, Essex, Longman Group Ltd. 
Soto, G. (2002): "La argumentación en artículos científicos escritos en español: superestructuras, evaluaciones y hedges". Ponencia presentada en el Congreso Internacional La Argumentación: Lingüistica, Retórica, Lógica, Pedagogía. Buenos Aires, Universidad de Buenos Aires, 10 a 12 de julio.

Zenteno, C. (1991): “Entificación o proposicionalización? Procesos sintácticos relacionados”. Lenguas Modernas, 18, págs. 23-33.

Zenteno, C. (1996): "La tendencia entificatoria en el discurso especializado". En M. Rodríguez y M. Farías (eds.): Investigación multidisciplinaria. Estrategias integradas de investigación en lingüistica, literatura y disciplinas afines. Santiago, Universidad de Santiago de Chile.

Zenteno, C. (1999): "Algunas propuestas para una aproximación textual al funcionamiento de las formas gramaticales". Ponencia presentada en el 3er Coloquio Latinoamericano de Estudios del Discurso. Santiago, Universidad de Chile, 5 a 9 de abril.

Zenteno, C. (2002): "Las nominalizaciones en el discurso científico". Ponencia presentada en el XIII Encuentro de la Sociedad Nacional de Profesores de Lenguas Extranjeras en la Enseñanza Superior. Santiago, Pontificia Universidad Catolica de Chile, 19 a 22 de marzo. 